\section{Association of Meloidogyne partityla with Nickel Deficiency and Mouse-ear of Pecan}

\author{
A.P. Nyczepir, ${ }^{1,4}$ B.W. Wood, ${ }^{2}$ and C.C. Reilly ${ }^{3}$ \\ U.S. Department of Agriculture, Agricultural Research Service, Southeastern \\ Fruit and Tree Nut Research Laboratory, 21 Dunbar Road, Byron, GA 31008
}

Additional index words. Carya illinoinensis, little-leaf, Criconemoides xenoplax, nutrient disorder, nutrition, replant disorder, ring nematode, root-knot nematode

\begin{abstract}
Pecan [Carya illinoinensis (Wangenh.) K. Koch] trees exhibit nickel(Ni) deficiency in certain orchard situations. The symptoms are manifest as either mouse-ear or replant disorder and in certain situations are associated with nematode parasitism. A field microplot study of pecan seedlings treated with either Meloidogyne partityla or Criconemoides xenoplax or both found that parasitism by $M$. partityla can result in enhancement in the severity of mouse-ear symptoms and a reduction in foliar Ni concentration. The Ni threshold for triggering morphological symptoms in young developing foliage was between 0.265 and $0.862 \mu \mathrm{g} \cdot \mathrm{g}^{-1}$ dry weight, while the threshold for rosetting was between 0.007 and 0.064 $\mu \mathrm{g} \cdot \mathrm{g}^{-1} \mathrm{dw}$. Results indicate that parasitism by $M$. partityla is a contributing factor to the induction of $\mathrm{Ni}$ deficiency in pecan and raises the possibility that nematode parasitism and Ni nutrition can be contributing factors to many plant maladies.
\end{abstract}

Pecan is a major worldwide tree-nut crop that is North America's most valuable native tree-nut, with worldwide cultivation and substantial production in the United States and Mexico (Wood, 1994; Wood et al., 1990). It is also becoming an increasingly common crop in several other Western Hemisphere countries (e.g., Argentina, Brazil, Chile, Peru, and Uruguay) and is a significant horticultural crop in Australia and South Africa. This tree crop is attacked by a wide variety of disease and insect pests that greatly reduce tree productivity if improperly managed. Pecan is also prone to exhibit certain trace element deficiencies (e.g., $\mathrm{Zn}$ ) when grown in nonhydrophilic oligotrophicsoils; consequently, such soils are alien to the hydrophilic eutrophic soils that typify its ecological niche in the river bottoms of the central and southern United States.

The mouse-ear(ME) or little leaf malady of pecan is a nutrient disorder that has manifest itself as far back as the early 1900's (Demaree, 1926) and has increasingly manifest itself more recently as an orchard "replant" disorder (Wood et al., 2004a). Both the ME and replant disorders have recently been found to be due to a nickel (Ni) deficiency, with timely foliar application of Ni correcting both disorders (Wood et al., 2004a; 2004b). Examination of Ni deficient trees sometimes, but not always, exhibited evidence of nematode damage, especially that of root-knot nematode.

The nematode species, Meloidogyne incognita (Kofoid and White) Chitwood and

Received for publication 15 Nov. 2005. Accepted for publication 16 Dec. 2005. The authors thank W.T. Taylor, Jr., T.L. Lewis, R.H. Adams, and J.E. Stuckey for technical assistance.

${ }^{1}$ Research nematologist.

${ }^{2}$ Research horticulturist.

${ }^{3}$ Research plant pathologist.

${ }^{4}$ To whom reprint requests should be addressed; e-mail anyczepir@saa.ars.usda.gov.
M. arenaria (Neal) Chitwood are known to attack pecan in Georgia. However, in 2002, the pecan root-knot nematode, $M$. partityla Kleynhans, was found on pecan in the southeastern U.S. and was associated with stressed trees exhibiting dead branches in the upper canopy and/or typical ME associated foliar symptoms (Nyczepir etal., 2002). This was the first report of M. partityla on pecan in Georgia and the third report of this nematode outside of South Africa (Kleynhans, 1986); which was where the original description occurred. Starr et al. (1996) first reported M. partityla from pecan in the U.S. in 1996. Additionally, the ring nematode, Criconemoides xenoplax Raski [= Mesocriconema xenoplax (Raski) Loof \& de Grisse], was detected in the same soil as M. partityla in certain of these ME orchards in Georgia. In 2003-04, a survey was conducted in the major pecan growing regions of Georgia to determine distribution of M. partityla and other Meloidogyne spp. (Nyczepir et al., 2004). Meloidogyne partityla and two unknown Meloidogyne spp. were the only root-knot nematode species found parasitizing pecan. Meloidogyne partityla was found in a greater number of samples and appears to be the dominant root-knot nematode species in pecan.

The occasional association of nematode damaged pecan root systems with symptoms of ME and pecan replant disorder indicates that nematode parasitism is potentially a factor that triggers ME and Ni deficiency on certain sites. The present study demonstrates that root parasitism by $M$. partityla influences the severity of ME symptoms in pecan trees.

\section{Materials and Methods}

Inoculum source and production. The $C$. xenoplax, which originated from a pecan orchard with ME symptoms in Leary, Ga., was cultured on 'Desirable' pecan seedlings; and M. partityla eggs, originating from a commercial pecan orchard with ME symptoms in Cobb, Georgia, were extracted directly from the roots of an individual tree. Identification of the root-knot nematode as $M$. partityla was confirmed via the esterase phenotype technique (Esbenshade and Triantaphyllou, 1985). Rootknot nematode eggs were extracted from pecan roots using the method described by Hussey and Barker (1973), whereas C. xenoplax was extracted from the culture medium using centrifugation (Jenkins, 1964).

Field microplot study. Approximately 4-week-old open-pollination 'Desirable' pecan seedlings were planted singly in bucket microplots (Barker, 1985) (25-cm-diameter $\times$ 31-cm-deep) containing $15,000 \mathrm{~cm}^{3}$ of steam pasteurized soil (96\% sand, $0 \%$ silt, 4\% clay, pH 7.0, 1.27\% organic matter) in May 2002. The soil was obtained from under pecan trees exhibiting typical ME symptoms in a commercial orchard located in Sumter County, Ga. Nickel(Ni) concentration in the soils within the immediate area of this orchard ranged between 15.41 to $20.02 \mathrm{ppm}$ and is usually sufficient for plant needs. Microplots were established in a shaded area (30\% shade) in the field in Byron, Georgia. In July 2002, after seedling survival was evident, the following nematode treatments were added per microplot: 1) 4,000 M. partityla eggs (Mp); 2) 4,000 C. xenoplax adults and juveniles $(\mathrm{Cx}) ; 3) 4,000$ C.xenoplax adults and juveniles $+4,000 \mathrm{M}$. partityla eggs $(\mathrm{Cx}+\mathrm{Mp})$; and 4) an untreated control. The soil in each microplot was infested with the respective nematode inoculum in $40 \mathrm{ml}$ total solution added to two furrows $(10 \mathrm{~cm}$ long $\times$ $3 \mathrm{~cm}$ wide $\times 7 \mathrm{~cm}$ deep) around each seedling. The soil in the untreated control microplots was inoculated with an egg/nematode-free soil extract suspension from the same $M$. partityla pecan orchard and C. xenoplax culture. Note that an unpasteurized field soil treatment also was included which contained 15 C. xenoplax per $100 \mathrm{~cm}^{3}$ soil and no detectable $M$. partityla. The experiment was arranged as a randomized complete block design with nine treatment replicates. Plants were watered as needed and received no fertilizer for the duration of the experiment, as the orchard soil possessed both macro and micronutrients at levels to satisfy the needs of pecan seedlings. Annual applications of fertilizer were not made because most fertilizers contain nickel as a trace contaminate and would thus confound the experiment. Also, limited space did not allow for additional treatments. Treatment trees were evaluated for ME severity in April 2003, May 2004, and May 2005. ME severity was based on the following scale derived for identification of Ni deficiency symptoms by Wood et al (2004a, 2004b): 1 = no Ni associated morphological distortions of leaflets or leaves (i.e., normal); $2=1 \%$ to $25 \%$ of leaflets on the seedling exhibiting Ni deficient morphological distortions (i.e., slightly blunted); $3=26 \%$ to $50 \%$ of leaflets exhibiting some degree of $\mathrm{Ni}$ associated morphological distortions; 4 = $>50 \%$ of leaflets exhibiting morphological distortions; $5=\# 4$, plus leaflet cupping; $6=$ 
$\# 5$, plus necrosis of leaflet tips; $7=\# 6$, plus necrosis of leaflet margins, crinkled leaflets, and dwarfed leaflets; $8=\# 7$, plus dwarfed shoots; $9=\# 8$, plus rosetting; and $10=\# 9$, plus tree death. Data were subjected to analysis of variance with the general linear model (GLM) procedure of SAS (SAS Institute, Cary, N.C.). Treatment means were separated with Fisher's protected least significant difference (LSD) test following a significant $F$-test. Nickel content of foliage from among the test trees exhibiting different degrees of $\mathrm{ME}$ symptoms (i.e., specifically ME rating 1, 2, 7, 9; see above), irregardless of nematode treatment, was determined by atomic absorption spectroscopy using standard techniques (Wood et al., 2004a) in May 2005, and was done to link ME severity class to tissue Ni concentration. Data were subjected to analysis of variance and treatment means separated with Student's $t$ test. In Aug 2005, nematode soil populations were determined by collecting and thoroughly mixing four soil cores $(2.5 \times 30 \mathrm{~cm}$ deep $)$ from each microplot. Nematodes were extracted from a $100-\mathrm{cm}^{3}$ subsample by elutriation (Byrd et al., 1976) and centrifugation (Jenkins, 1964) and then counted.

Table 1. Mouse-ear (ME) severity in open pollinated 'Desirable' pecan seedlings grown in field microplots and evaluated nine, 21, and 33 months after inoculation with Meloidogyne partityla or Criconemoides xenoplax alone and in combination $(\mathrm{n}=9){ }^{\mathrm{z}}$

\begin{tabular}{lccc}
\hline & \multicolumn{3}{c}{ Mouse-ear severity rating $^{y}$} \\
\cline { 2 - 4 } Treatment & Apr. 2003 & May 2004 & May 2005 \\
\hline M. partityla $(\mathrm{Mp})$ & $8.3 \mathrm{a}^{\mathrm{x}}$ & $8.2 \mathrm{a}$ & $9.2 \mathrm{a}$ \\
Mp + Cx & $7.6 \mathrm{ab}$ & $5.2 \mathrm{c}$ & $7.4 \mathrm{a}$ \\
Unpasteurized soil & $5.9 \mathrm{bc}$ & $7.3 \mathrm{ab}$ & $6.9 \mathrm{a}$ \\
C. xenoplax $(\mathrm{Cx})$ & $5.9 \mathrm{bc}$ & $6.7 \mathrm{abc}$ & $6.8 \mathrm{a}$ \\
Untreated control & $4.6 \mathrm{c}$ & $6.6 \mathrm{bc}$ & $6.4 \mathrm{a}$ \\
\hline
\end{tabular}

${ }^{2}$ Initial population density of Meloidogyne partityla $=267 \mathrm{eggs} / 100 \mathrm{~cm}^{3}$ soil, Criconemoides xenoplax $=$ 267 juveniles and adults $/ 100 \mathrm{~cm}^{3}$ soil, and $\mathrm{Mp}+\mathrm{Cx}=267 \mathrm{Mp}+267 \mathrm{Cx} / 100 \mathrm{~cm}^{3}$ soil.

${ }^{y} \mathrm{ME}$ severity was based on the following foliar symptom class scale: $1=$ no $\mathrm{Ni}$ associated morphological distortions of leaflets or leaves (i.e., normal); $2=1 \%$ to $25 \%$ of leaflets on the seedling exhibiting N deficient morphological distortions (i.e., slightly blunted); $3=26 \%$ to $50 \%$ of leaflets exhibiting some degree of $\mathrm{Ni}$ associated morphological distort; $4=>50 \%$ of leaflets exhibiting morphological distortion; $5=\# 4$, plus leaflet cupping; $6=\# 5$, plus necrosis of leaflet tips; $7=\# 6$, plus necrosis of leaflet margins, crinkled leaflets, and dwarfed leaflets; $8=\# 7$, plus dwarfed shoots; $9=\# 8$, plus rosetting; and $10=\# 9$, plus tree death.

${ }^{\times}$Means in columns followed by the same letters are nonsignificant $(P \leq 0.05)$, Fisher's protected LSD.

Table 2. Nickel concentrations in young leaflets of open pollinated 'Desirable' pecan seedlings exhibiting different degrees of mouse-ear (ME) symptoms due to nematode treatment and grown in field microplots 33 months after inoculation with Meloidogyne partityla or Criconemoides xenoplax alone and in combination $^{\mathrm{z}}$.

\begin{tabular}{lc}
\hline Foliar symptom class ${ }^{y}$ & $\begin{array}{c}\text { Ni concn } \\
\left(\mu g \cdot \mathrm{g}^{-1} \mathrm{dry} \text { wt }\right)\end{array}$ \\
\hline Normal (Class =1) & $0.862 \mathrm{a}^{\mathrm{x}}$ \\
Slightly blunted leaflets (Class =2) & $0.265 \mathrm{~b}$ \\
Dwarfed and blunted leaflets with tip necrosis, curved margins, and crinkling (Class $=7)$ & $0.064 \mathrm{c}$ \\
Class 7, plus dwarfed shoots and rosetting (Class =9) & $0.007 \mathrm{~d}$ \\
\hline
\end{tabular}

${ }^{\mathrm{z}}$ Leaflet sample taken near the end of canopy expansion in late May 2005, from both the untreated contro plots and nematode-inoculated plots with an initial population density of Meloidogyne partityla $=267$ eggs $/ 100 \mathrm{~cm}^{3}$ soil, Criconemoides xenoplax $=267$ juveniles and adults $/ 100 \mathrm{~cm}^{3}$ soil, and $\mathrm{Mp}+\mathrm{Cx}=267$ $\mathrm{Mp}+267 \mathrm{Cx} / 100 \mathrm{~cm}^{3}$ soil. Leaflet samples were composited within a respective foliar symptom class regardless of treatment.

${ }^{\mathrm{y}} \mathrm{ME}$ severity was based on the following foliar symptom class scale: 1 = no Ni associated morphological distortions of leaflets or leaves (i.e., normal); $2=1 \%$ to $25 \%$ of leaflets on the seedling exhibiting Ni deficient morphological distortions (i.e., slightly blunted); $3=26 \%$ to $50 \%$ of leaflets exhibiting some degree of $\mathrm{Ni}$ associated morphological distort; $4=>50 \%$ of leaflets exhibiting morphological distortion; $5=\# 4$, plus leaflet cupping; $6=\# 5$, plus necrosis of leaflet tips; $7=\# 6$, plus necrosis of leaflet margins, crinkled leaflets, and dwarfed leaflets; $8=\# 7$, plus dwarfed shoots; $9=\# 8$, plus rosetting; and $10=\# 9$, plus tree death.

${ }^{x}$ Means in columns followed by the same letters are nonsignificant $(P \leq 0.05)$, Student's $t$ test. leaflet analysis. Average nematode soil population densities were as follows: 1) M. partityla (23 Mp J2/100 $\mathrm{cm}^{3}$ soil), 2) C. xenoplax $\left(1,052 \mathrm{Cx} / 100 \mathrm{~cm}^{3}\right.$ soil $\left.), 3\right) \mathrm{Mp}+\mathrm{Cx}$ (17 Mp $\mathrm{J} 2 \& 38 \mathrm{Cx} / 100 \mathrm{~cm}^{3}$ soil, respectively), and 4) unpasteurized field soil (5 Mp J2 and 183 $\mathrm{Cx} / 100 \mathrm{~cm}^{3}$ soil, respectively). The presence of M. partityla appeared to suppress the population density of $C$. xenoplax 33 months after inoculation as compared to C.xenoplax alone. The results indicate biological antagonism between the nematode species and that host specificity is shifted in favor of M. partityla, since more severe ME symptoms occurred in the presence of this nematode alone. Further investigations are warranted to clarify these observations.

The severity of ME symptoms in the current study was inversely proportional $(P \leq 0.05)$ to $\mathrm{Ni}$ concentration in the pecan leaflets (Table 2), thus supporting earlier findings that ME severity in pecan is due to a physiological nickel deficiency (Wood et al., 2004a). In that same study, Wood et al. (2004a) also demonstrated that severe ME symptoms can be reversed in subsequent shoot, leaf and leaflet growth following $\mathrm{Ni}$ application immediately after budbreak in the spring. Seedlings exhibited morphologically normal canopy (leaflet and shoot) growth when foliar $\mathrm{Ni}$ content was $\geq 0.862 \mu \mathrm{g} \cdot \mathrm{g}^{-1}$ dry weight under the conditions of our trial (Table 2). The foliar Ni content of leaflets exhibiting slight morphological foliar distortions (i.e., leaflet blunting) contained $\mathrm{Ni}$ at $0.265 \mu \mathrm{g} \cdot \mathrm{g}^{-1}$ dry weight; thus it appears that the threshold leading to morphological distortion of young developing foliage is a $\mathrm{Ni}$ concentration between 0.265 and $0.862 \mu \mathrm{g} \cdot \mathrm{g}^{-1}$ dry weight. The Ni threshold for marginal necrosis and wrinkled lamina (crinkling) is between 0.064 and $0.265 \mu \mathrm{g} \cdot \mathrm{g}^{-1}$ dry weight, whereas that for rosetting appears to be between 0.007 and $0.064 \mu \mathrm{g} \cdot \mathrm{g}^{-1}$ dry weight. These threshold concentrations indicate that morphological evidence of Ni deficiency is not manifested until Ni concentrations are below ca. $0.862 \mu \mathrm{g} \cdot \mathrm{g}^{-1}$ dry weight during the time of leaf expansion. One explanation for nickel deficiency, or ME, in certain pecan orchards is that root parasitism by $M$. partityla is potentially affecting the absorption and/or translocation of the $\mathrm{Ni}$ or other metals that influence the physiological availability of Ni. Identification of the mechanism of action therefore requires additional research.

The present study indicates that severity of ME symptoms, and thus Ni deficiency, in pecan trees can potentially be triggered or enhanced by parasitism of roots by $M$. partityla. The parasitic habit of $M$. partityla likely affects the timely absorption and subsequent translocation of the Ni to aerial organs, thus disrupting plant metabolism and visually detectable growth processes when the Ni concentration of young expanding foliage is between $0.265 \mu \mathrm{g} \cdot \mathrm{g}^{-1}$ and $0.862 \mu \mathrm{g} \cdot \mathrm{g}^{-1}$ dry weight. Results also indicate that parasitism by C. xenoplax appears to have little or no influence on ME severity or $\mathrm{Ni}$ nutrition of pecan. The interactions of nematode parasitism and plant Ni nutrition merits further study in regards to several complex 
replant diseases or disorders exhibited by a wide variety of woody perennial crops.

\section{Literature Cited}

Barker, K.R. 1985. Design of greenhouse and microplot experiments for evaluation of plant resistance to nematodes, p. 107-113 In: B.M. Zuckerman, W.F. Mai, and M.B. Harrison (eds.). Plant nematology laboratory manual. Univ. Mass. Agr. Expt. Sta., Amherst, Mass.

Byrd, Jr., D.W., K.R. Barker, H. Ferris, C.J. Nusbaum, W.E. Griffin, R.H. Small, and C.A. Stone. 1976. Two semi-automatic elutriators for extracting nematodes and certain fungi from soil. J. Nematol. 8:206-212.

Demaree, J.B. 1926. Little leaf disease of pecans. Phytopathology 16:277-283.

Esbenshade, P.R. and A.C. Triantaphyllou. 1985.
Use of enzyme phenotypes for identification of Meloidogyne species. J. Nematol. 17:6-20.

Hussey, R.S. and K.R. Barker. 1973. A comparison of methods of collecting inocula of Meloidogyne spp., including a new technique. Plant Dis. Rpt. 57:1025-1028.

Jenkins, W.R. 1964. A rapid centrifugal-flotation technique for separating nematodes from soil. Plant Dis. Rpt. 48:692.

Kleynhans, K.P.N. 1986. Meloidogyne partityla sp. nov. from pecan nut [Carya illinoinensis (Wangenh.) C. Koch] in the Transvaal Lowveld (Nematoda: Meloidogynidae). Phytophylactica 18:103-106.

Nyczepir, A.P., C.C. Reilly, B.W. Wood, and S.H. Thomas. 2002. First record of Meloidogyne partityla on pecan in Georgia. Plant Dis. 86:441.

Nyczepir, A.P., C.C. Reilly, and B.W. Wood. 2004. Incidence and association of Meloidogyne partityla with mouse-ear disorders of pecan in Georgia. J. Nematol. 36:338.

Starr, J.L., E.K. Tomaszewski, M. Mundo-Ocampo, and J.G. Baldwin. 1996. Meloidogyne partityla on pecan: Isozyme phenotypes and other hosts. J. Nematol. 28:565-568.

Wood, B.W. 1994. Edible tree nuts: Pecan and other hickories. Encycl. Agr. Sci. 2:1-8.

Wood, B.W., C.C. Reilly, and A.P. Nyczepir. 2004a. Mouse-ear of pecan: A nickel deficiency. HortScience 39:1238-1242.

Wood, B.W., C.C. Reilly, and A.P. Nyczepir. 2004b. Mouse-ear of pecan: II. Influence of nutrient applications. HortScience 39:95-100.

Wood, B.W., J.A. Payne and L.J. Grauke. 1990. The rise of the United States pecan industry. HortScience 25:594, 721-723. 